\title{
Evaluation of high-degree series expansions of the topographic potential to higher-order powers
}

\author{
Christian Hirt $^{1}$ and Michael Kuhn ${ }^{1}$ \\ Received 30 May 2012; revised 11 October 2012; accepted 22 October 2012; published 19 December 2012.
}

[1] Mass associated with surface topography makes a significant contribution to the Earth's gravitational potential at all spectral scales. Accurate computation in spherical harmonics to high degree requires calculations of multiple integer powers of the global topography. The purpose of this paper is to analyze the contributions of Earth's topography to its potential to the tenth power of the topography, and quantify truncation errors resulting from neglecting higher-order powers. To account for the effect of gravity attenuation with height, we use series expansions for gravity upward-continuation to the Earth's surface. With degree-2160 expansions, limitation to the first three powers of the topography, as often done in practice, may give rise to maximum truncation errors exceeding $100 \mathrm{mGal}$ at a reference sphere, and $\sim 25 \mathrm{mGal}$ at the topography. Aiming for a maximum truncation error of $1 \mathrm{mGal}$ we found that higher-order terms to the seventh power are required over the Himalaya Mountains as example of Earth's most rugged land region. Upward-continuation of topographic gravity effects with mGal-precision from the sphere to the Earth's surface is accomplished with a series expansion of fifth order. As a key finding, the accurate conversion of topography to gravity effects at the Earth's surface is governed by two similar yet not identical series expansions. For degree-2160 expansions, we recommend that the powers of Earth's topography be used up to seventh order to accurately evaluate the topographic potential to the mGal-level, as required, e.g., for the construction of high-resolution Bouguer gravity anomaly maps in spherical harmonics.

Citation: Hirt, C., and M. Kuhn (2012), Evaluation of high-degree series expansions of the topographic potential to higher-order powers, J. Geophys. Res., 117, B12407, doi:10.1029/2012JB009492.

\section{Introduction}

[2] Series expansions of the topographic gravitational potential (i.e., the gravitational potential induced by topographic masses, hereafter called topographic potential) in spherical harmonics are a universal tool for the transformation of a planet's topography to implied potential and gravity effects. Previous studies have used this transformation for a wide range of applications, such as comparisons of the Earth's topography and/or isostatic compensation masses with the observed gravity field [e.g., Rummel et al., 1988; Tsoulis, 2001; Göttl and Rummel, 2009; Novák, 2010a; Hirt et al., 2012], the computation of spherical harmonic Bouguer anomalies for the Moon [Wieczorek and Phillips, 1998], Mars [Neumann et al., 2004] and Earth [Balmino et al., 2012]. Further applications include, but are not limited to, estimations of the Moho density contrast [Martinec, 1994], inversion of magnetic anomalies [Parker and Huestis, 1974], computation of topographic effects in geoid determination

\footnotetext{
${ }^{1}$ Institute for Geoscience Research, Curtin University, Perth, Western Australia, Australia.

Corresponding author: C. Hirt, Institute for Geoscience Research, Curtin University, GPO Box U1987, Perth, WA 6845, Australia. (c.hirt@curtin.edu.au)

(C)2012. American Geophysical Union. All Rights Reserved. 0148-0227/12/2012JB009492
}

[e.g., Vaníček et al., 1995; Sjöberg, 2000; Heck, 2003] and gravity reductions [Nahavandchi and Sjöberg, 1998], topographic effects in satellite gravity gradiometry [e.g., Wild and Heck, 2005; Makhloof and Ilk, 2008; Eshagh, 2010], and cross-comparisons with Newton's integral in the spatial domain [Kuhn and Seitz, 2005].

[3] Because the relation between topographic height function and topographic potential is nonlinear [Rummel et al., 1988; Wieczorek, 2007], the topographic potential is usually expanded into a series of powers of the topographic heights. The necessity for nonlinear terms was pointed out early by Jung [1952]. Rummel et al. [1988] derived the contributions of Earth's topography to the topographic potential up to thirdorder, and studied these for degree-180 harmonic models. Balmino [1994] generalized the transformation to higher orders. Wieczorek and Phillips [1998] expressed the relation between gravity and topography as an infinite series expansion and studied the truncation errors for the Moon's topographic potential. Chambat and Valette [2005] studied the secondorder contributions to the topographic potential. Wieczorek [2007] investigated the truncation errors for the terrestrial planets and found truncation errors at the level of some mGal for third-order expansions of Earth's topography to degree $\sim 360$ (M. A. Wieczorek, personal communication, 2012).

[4] In the presence of the degree-2160 EGM2008 Earth geopotential model (http://earth-info.nga.mil/GandG/wgs84/ gravitymod/egm2008) [Pavlis et al., 2008, 2012], series 
expansions are used nowadays to compute the potential of Earth's topography with a comparable [Makhloof, 2007; Novák, 2010a; Bagherbandi, 2011; Bagherbandi and Sjöberg, 2012] or even higher (to degree 5400, cf. Novák [2010b] and Gruber et al. [2012]; to degree 10,800, cf. Balmino et al. [2012]) resolution. Many of the recent works truncate the series expansions of the topographic potential after three orders, as such seemingly relying on findings for degree-360 models of Earth's topography. Exceptions are Tenzer et al. [2011a] and Novák [2010b] who computed the first five powers of the topographic potential. Some researchers acknowledge that terms higher than third-order might be required. For example, Makhloof [2007, p. 101] states that "at least the first, second and third terms of height must be taken into account for calculating the gravitational effect"; Balmino et al. [2012, section 6] note that "a truncation at the third power is probably not sufficient in areas of high/rough topography"; and Tenzer et al. [2011a, p. 620] find that using up to fifth order will result into a relative accuracy of better than $0.016 \%$ when modeling gravitational effects of ocean water masses to degree 360 , while pointing out that "a careful analysis of the convergence and optimal truncation $[\ldots]$ is needed when using a higher than 360 degree of a spectral resolution." With the exception of Novák [2010b], little attempt is made in most of the previous works to quantify or reduce the truncation error of third-order series expansions and degree-2160 models by including the higher-order terms.

[5] The aim of this study is to investigate the accurate evaluation of series expansions of the topographic potential for degree-2160 Earth topography models. By analyzing the signal strengths and examining the truncation errors, this study provides answers on the role of the neglected higherorder terms. From a range of functionals of the topographic potential, we exemplify the evaluation for the topographic gravity effect, which is technically the radial derivative of the topographic potential.

[6] We place a first focus on determination and analysis of the topographic potential degree variance spectra of the first ten powers of Earth's topography. A second focus is on quantifying the truncation errors for topographic gravity effects over mountainous test areas. Because some practical applications require evaluation of topographic gravity effects at the Earth's surface rather than a reference sphere, we put a third focus on emerging 3D spherical harmonic synthesis (SHS) methods capable of providing topographic gravity effects that account for the effect of gravity attenuation with height. This is required in practical applications involving topographic reductions of observed surface gravity, as is the case with the geophysically defined Bouguer gravity anomaly, which is defined at the Earth's surface [e.g., Hackney and Featherstone, 2003a, 2003b, 2006; Kuhn et al., 2009]. Our 3D-SHS is based on gravity upward-continuation using an efficient higher-order gradient approach [Hirt, 2012; Balmino et al., 2012]. This allows us to study the contribution of the higher-order series expansion terms and truncation errors not only at the surface of a reference sphere but also at the Earth's surface as represented by topographic models.

[7] Numerical case studies over the Mount Everest region (representing Earth's most elevated and rugged land region), and the European Alps region (as an example of a more medium-elevated mountain range) are used to quantify truncation errors for degree-2160 topography models. We believe the choice of this resolution is justified by the fact that EGM2008 is now a de-facto standard reference model used by a wide geo-scientific community, and the topographic potential is required to the same resolution for some applications. We demonstrate that in spherical harmonic representation the practical evaluation of topographic gravity effects at the Earth's surface is governed by two closely related series expansions (the transformation of topography to topographic potential, and 3D-SHS for the upwardcontinuation). With the principles used in this study, truncation errors can be quantified for other planetary bodies, and/or higher resolution topography models, and/or other functionals of the topographic potential.

\section{Mathematical Approach}

\subsection{Series Expansions of the Topographic Potential}

[8] Series expansions of the topographic potential have been derived several times in the literature [see, e.g., Rummel et al., 1988, p. 3; Wieczorek and Phillips, 1998, p. 1716; Ramillien, 2002, p. 144; Eshagh, 2010, p. 663]. Principally, these derivations start from the fundamental Newton's integral in the space domain, replace the inverse distance in this integral through a series of Legendre polynomials and expand the heights of the topography into a binomial series, see the above references. Note that a variety of terms are in use in the literature for series expansions of the topographic potential, e.g., gravitational potential created by the topography [Ramillien, 2002], Newton's integral in spherical harmonic expansion [Kuhn and Featherstone, 2003], transformation of gravity to topography [Wieczorek, 2007] or (computation of) Bouguer coefficients [Balmino et al., 2012].

[9] Let $H^{p}$ denote topographic heights of power $p$ in the space domain, and $H_{n m}^{p}$ the short-hand for the fully normalized spherical harmonic coefficients $(\overline{H C}, \overline{H S})_{n m}^{p}$ of the topography of power $p$ with $n$ degree and $m$ order. The coefficients $H_{n m}^{p}$ are related to $H^{p}$ through the spherical harmonic expansion

$$
H^{p}=\sum_{n=0}^{n \max } \sum_{m=0}^{n}\left(\overline{H C}_{n m}^{p} \cos m \lambda+\overline{H S}_{n m}^{p} \sin m \lambda\right) \bar{P}_{n m}(\sin \varphi)
$$

where $n_{\max }$ denotes the maximum degree of expansion (here 2160), $\lambda$ the longitude and $\varphi$ geocentric latitude of the computation point. $\bar{P}_{n m}(\sin \varphi)$ are the $4 \pi$-fully normalized associated Legendre functions of degree $n$ and order $m$. After introducing some constant reference radius $R$ (e.g., mean Earth radius), the dimensionless height function

$$
H^{(p)}=\frac{H^{p}}{R^{p}}
$$

describes the $R$-normalized and laterally variable topographic heights of power $p$ in the space domain and

$$
H_{n m}^{(p)}=\frac{H_{n m}^{p}}{R^{p}}
$$

in the spectral domain. The series expansions of the topographic potential describe the transformation of the height 
functions $H_{n m}^{(p)}$ to power $p=p_{\max }$ to the topographic potential $V_{n m}^{p \max }$ [after Rummel et al., 1988; Balmino, 1994; Wieczorek and Phillips, 1998]

$$
V_{n m}^{p \max }=\frac{3}{2 n+1} \frac{\rho}{\bar{\rho}} \sum_{p=1}^{p \max } \frac{\prod_{i=1}^{p}(n+4-i)}{p !(n+3)} H_{n m}^{(p)}
$$

where $\rho$ is the (constant) mass-density of the topography and $\bar{\rho}$ is the mean (bulk) mass-density of the planet. $V_{n m}^{p \max }$ is the short-hand for the fully normalized spherical harmonic coefficients $(\overline{V C}, \overline{V S})_{n m}^{p \max }$ of the topographic potential obtained from equation (4). Instead of a constant $\rho$, laterally varying mass-density values $\rho_{i}$ could be used by replacing the topographic heights $H^{p}$ with products of $H^{p}$ and $\rho_{i}$ [see, e.g., Kuhn and Featherstone, 2003; Novák and Grafarend, 2006; Wieczorek, 2007]. Three-dimensional density functions can be used for some simple functions of the geocentric radius (e.g., polynomials [see Tenzer et al., 2011b]). In this study we use the common case of constant mass-density for topographic masses.

[10] According to Wieczorek [2007], $p_{\max }=1$ corresponds to the Bouguer shell effect (i.e., Bouguer plate correction), and terms $p_{\max }>1$ can be interpreted as terrain correction to the Bouguer shell in spherical harmonics (adding the third dimension). For $p$ larger than 3, all coefficients $V_{n m}^{(p)}$ with $n<$ $p-3$ are zero, so do not contribute to $V_{n m}^{p \max }$, cf. Balmino $[1994$, p. 335]. It is the products of the degree-dependent factors (the $(n+4-i)$-terms in equation (4)) which cause an increasingly larger contribution of higher-order powers of the topography as the degree $n$ increases (section 3.1). Explicit forms of the $V_{n m}^{(p)}$-terms are given in the Appendix to $p_{\max }=10$.

[11] While modeling the full spectrum requires (theoretically) an infinite expansion of equation (4) (that is, $n_{\max }$ and $p_{\max }$ are infinite), for a band-limited spectrum ( $n_{\max }$ is finite) the exact transformation of topography to its topographic potential requires expansion of equation (4) to only $p_{\max }=$ $n_{\max }+3$. This is because for higher-order terms the leading factor becomes zero. In practical applications, however, limitation to a much smaller number of terms is sufficient to force truncation errors below a certain threshold (e.g., related to the precision of gravimetric measurements). Parameter $p_{\max }$ is influenced by a range of factors such as the resolution of the topography $\left(n_{\max }\right)$, the planetary body under consideration [see Wieczorek, 2007, Figure 9], the height of evaluation of topographic gravity effects, and the threshold below which truncation errors are considered acceptable. The investigation of $p_{\max }$ at different evaluation heights (surface of reference sphere and height of the topography) is treated for Earth and $n_{\max }=2160$ in the numerical case study (section 3).

[12] The topographic potential coefficients $V_{n m}^{p \max }$ are converted to topographic gravity effects $\delta g^{p \max }$ as radial derivative of the topographic potential

$$
\begin{aligned}
\delta g^{p \max }(\varphi, \lambda, r)= & -\frac{\partial V}{\partial r}=\frac{G M}{r^{2}} \sum_{n=2}^{n \max }(n+1)\left(\frac{R}{r}\right)^{n} \\
& \cdot \sum_{m=0}^{n}\left(\overline{V C}_{n m}^{p \max } \cos m \lambda+\overline{V S}_{n m}^{p \max } \sin m \lambda\right) \bar{P}_{n m}(\sin \varphi)
\end{aligned}
$$

where $G M$ is the product of the universal gravitational constant and planetary mass, and $(\varphi, \lambda, r)$ are the $3 \mathrm{D}$ coordinates of the evaluation point ( $\lambda$ longitude, $\varphi$ geocentric latitude and $r$ geocentric radius). The factor $(R / r)^{n}$ is known as attenuation factor and plays an important role in this study (see section 2.2 and 3.2).

[13] To accurately reduce (full-spectrum) gravity observations from terrestrial gravimetry, topographic gravity effects from truncated (e.g., $n_{\max }=2160$ ) spherical harmonic models are not sufficient. This is because observed gravity data possess spectral energy at all spatial scales [e.g., Torge, 2001], while the spherical harmonic model cannot represent short-scale topographic gravity effects (here at scales less than 5 arc-min). This effect, known as (signal) omission error, can be taken into account in the spatial domain using high-resolution digital elevation data and, e.g., the residual terrain modeling technique (RTM) [Forsberg, 1984].

[14] Given that omission errors can reach magnitudes of $\sim 100 \mathrm{mGal}$ or more in case of EGM2008 [e.g., Hirt, 2012, Table 5], it is clear that the resolution of degree-2160 topography models cannot guarantee $1 \mathrm{mGal}$ accuracy in the absolute sense, e.g., for the purpose of reducing (fullspectrum) gravity observations. Here we focus on accurate spherical harmonic modeling of topographic gravity effects, band-limited to 5 arc-min resolution, which is commensurate with the EGM2008 geopotential model. For modeling of short-scale topographic gravity effects beyond the resolution of spherical harmonic models see, e.g., Pavlis et al. [2007] and Hirt et al. [2011]. Omission error modeling is not further dealt with in this study.

\subsection{Continuation to the Earth's Surface}

[15] For all comparisons or reductions involving gravity measurements, topographic gravity effects are required at the 3D-location $(\varphi, \lambda, r)_{Q}$ of the gravity station at the point $Q$ at Earth's surface rather than at the surface of the reference sphere. As an example, we name the geophysically defined Bouguer anomaly where the topographic effect is reduced at gravity station height [e.g., Hackney and Featherstone, 2003a, 2003b, 2006]. There are two ways to accomplish the 3D-SHS of topographic gravity effects:

[16] 1. Direct evaluation of equation $(5)$ at $(\varphi, \lambda, r)_{Q}$ the locations of the gravity stations. For high-degree (say $n_{\max }$ beyond $\sim 1000$ ) SHS at multiple points arranged in regularly spaced latitude-longitude grids, the direct SHS approach is very time-consuming [e.g., Holmes, 2003]. This is because numerically efficient algorithms for high-degree SHS [e.g., Tscherning and Poder, 1982; Holmes and Featherstone, 2002; Holmes and Pavlis, 2008] require a constant $(R / r)^{n}$ attenuation factor along the parallels of the latitude-longitude grid. Earth's topography makes the $\left(R / r_{Q}\right)^{n}$-factor a varying quantity along parallels, preventing the direct use of efficient high-degree SHS algorithms [e.g., Hirt, 2012].

[17] 2. (Upward)-continuation of $\delta g$ from the reference sphere $(\varphi, \lambda, R)$ to $\left(\varphi, \lambda, r_{Q}\right)$ using Taylor series expansions. These provide an efficient solution to 3D-SHS of topographic gravity effects at multiple grid points because the $\delta g$ and the radial derivatives of $\delta g$ are evaluated at some constant $r$, which enables the use of efficient SHS algorithms. 
Hirt [2012] investigated the use of higher-order gradients for the upward-continuation of gravity effects from the EGM2008 geopotential model. As we will show here, this technique is equally suited for efficient yet accurate SHS of topographic gravity effects from the topographic potential.

[18] While the direct evaluation of $\delta g$ at $(\varphi, \lambda, r)_{Q}$ is of course feasible for a smaller number (say thousands) of scattered points, it is too time consuming for multiple (say millions) densely spaced grid points. We therefore investigate Taylor series expansions to degree $k_{\max }$ for the continuation of gravity effects to the Earth's surface

$$
\left.\delta g_{Q}^{k \max }\left(\varphi, \lambda, r_{Q}\right) \approx \sum_{k=0}^{k \max } \frac{1}{k !} \frac{\partial^{k} \delta g}{\partial r^{k}}\right|_{r=R} H^{k}
$$

where $H$ is the elevation of the point $P$, and $\partial^{k} \delta g / \partial r^{k}$ is the radial derivative of order $k(k>0)$ computed from [Hirt, 2012]

$$
\begin{aligned}
\frac{\partial^{k} \delta g}{\partial r^{k}}= & (-1)^{k} \frac{G M}{r^{k+2}} \sum_{n=2}^{n \max }(n+1)\left\{\prod_{i=1}^{k}(n+i+1)\right\}\left(\frac{R}{r}\right)^{n} \\
& \times \sum_{m=0}^{n}\left(\overline{V C}_{n m}^{p \max } \cos m \lambda+\overline{V S}_{n m}^{p \max } \sin m \lambda\right) \bar{P}_{n m}(\sin \varphi)
\end{aligned}
$$

at the surface of the sphere $r=R$. The 0 -th derivative is the topographic gravity itself (equation (5)) at $r=R$. To improve the convergence of the upward-continuation (section 3.3), it is advantageous to evaluate $\partial^{k} \delta g / \partial r^{k}$ at a mean reference elevation $H_{\text {ref }}$ (e.g., $4000 \mathrm{~m}$ ) above the reference radius $R$

$$
\left.\delta g_{Q}^{k \max }\left(\varphi, \lambda, r_{Q}\right) \approx \sum_{k=0}^{k \max } \frac{1}{k !} \frac{\partial^{k} \delta g}{\partial r^{k}}\right|_{r=R+H_{r e f}}\left(H-H_{r e f}\right)^{k}
$$

where $H-H_{r e f}$ is the elevation of point $Q$ relative to $H_{r e f}$, and the radial derivatives are evaluated at $r=R+H_{\text {ref. }}$. As main advantage of equations (6)-(8) over equation (5), height information $H$ (e.g., from digital elevation models) can be taken into account globally at high-resolution, say a few arc minutes or higher, within reasonable computation times [Hirt, 2012], while keeping the SHS computations and use of height information separated. We note that equations (6) and (8) are valid only if the series expansion exists and converges, which has not been proven here. However, numerical evaluations suggest that they can be used for practical computations.

[19] We acknowledge that Balmino et al. [2012] also use Taylor series expansions for gravity upward-continuation in place of the direct 3D SHS, however, without using mean reference elevations $H_{\text {ref }}$ to accelerate the convergence. We note equations (6) and (7) are similar to the frequently used analytical downward-continuation of gravity measurements, as described in Moritz [1980]. While Moritz's approach (downward)-continues gravity in the spatial domain, from the Earth's surface to some reference surface inside Earth, our approach continues gravity in the spectral domain, from some reference surface $R+H_{r e f}$ to the Earth' surface, as represented through elevation $H$. Thus, the upward-continuation approach taken here is suitable for topographic reductions at the Earth's surface (as is done in geophysics) while Moritz's approach is used in geodesy in the context of gravimetric geoid determination.

\section{Numerical Study}

[20] The rationale of the numerical study is to analyze how the $V_{n m}^{(p)}$ of Earth's topography contribute to Earth's topographic potential $V_{n m}^{p \max }$ and gravity effects $\delta g$ and to examine the truncation errors of topographic gravity effects at the reference sphere and at the topography. As highresolution spherical harmonic model of Earth's topography, we use the DTM2006.0 model [Pavlis et al., 2007, 2012] in all of our numerical tests. DTM2006.0 is a companion product of EGM2008 [Pavlis et al., 2012] and provides harmonic coefficients $\left(\overline{H C}^{*}, \overline{H S}^{*}\right)_{n m}$ of the Earth's solid surface (i.e., ocean depths over sea and topographic heights of the land/air interface elsewhere) which are used here to degree $n_{\max }=2160$. Among other data sources, DTM2006.0 relies on SRTM (Shuttle Radar Topography Mission) elevations within the SRTM data coverage, altimetry-derived bathymetry, and ICESat-2 ice altimetry over Greenland and Antarctica, see Pavlis et al. [2012] for more details.

\subsection{Computation of Earth's Topographic Potential}

[21] We make use of the concept of rock-equivalent topography (RET) [see e.g., Rummel et al., 1988] which is convenient because a single constant mass-density value can be used to describe the topographic masses over land, ocean and ice. Following steps were taken to compute the topographic potential contributions of Earth's topography to tenth power.

[22] 1. We first evaluated the DTM2006.0 $\left(\overline{H C}^{*}, \overline{H S}^{*}\right)_{n m}$ fully normalized coefficients to $n_{\max }=2160$ into a regularly spaced $2^{\prime} \times 2^{\prime}$ grid of geocentric latitude and longitude using the harmonic_synth spherical harmonic synthesis software [Holmes and Pavlis, 2008]. Note we use the "asterisks" symbol in order to distinguish above coefficients from that of the RET elevations (cf. point 3 below).

[23] 2. We then compressed the ocean water masses as well as ice masses of the ice sheets over Greenland and Antarctica to RET of a constant mass-density of $\rho=2670 \mathrm{~kg}$ $\mathrm{m}^{-3}$ using the procedure described in Hirt et al. [2012].

[24] 3. We used the SH-Tools (http://shtools.ipgp.fr/) implementation of Driscoll and Healy's [1994] algorithm for spherical harmonic analysis (SHA) of the $2^{\prime} \times 2^{\prime}$ grid of RET elevations. This gave us the $H_{n m}^{(1)}=(\overline{H C}, \overline{H S})_{n m}$ coefficients of Earth's RET to degree 2700, from which we use all coefficients to $n_{\max }=2160$ [see also Pavlis et al., 2007].

[25] 4. In the same manner, we derived the $H_{n m}^{(p)}$ coefficients of the squared, cubed and higher-order powers of the dimensionless RET to $p=10$, by first forming the powers $p$ of the $2^{\prime} \times 2^{\prime}$ RET elevations, then normalizing the RET elevations with equation (2) and a constant reference radius $R=6,378,137 \mathrm{~m}$ (semi-major axis of the Geodetic Reference System 1980 [cf. Moritz, 2000]), before applying Driscoll and Healy's algorithm. Thus, ten SHA gave us 10 sets of $2,336,041 H_{n m}^{p}$ coefficient pairs to $n_{\max }=2160$.

[26] 5. Finally, we computed the contributions $V_{n m}^{(p)}$ of the powers of the RET as well as the total contribution of all powers to $p=10$ using equation (4) with $\rho=2670 \mathrm{~kg} \mathrm{~m}^{-3}$ and $\bar{\rho}=5515 \mathrm{~kg} \mathrm{~m}^{-3}$ [cf. Torge [2001]. 


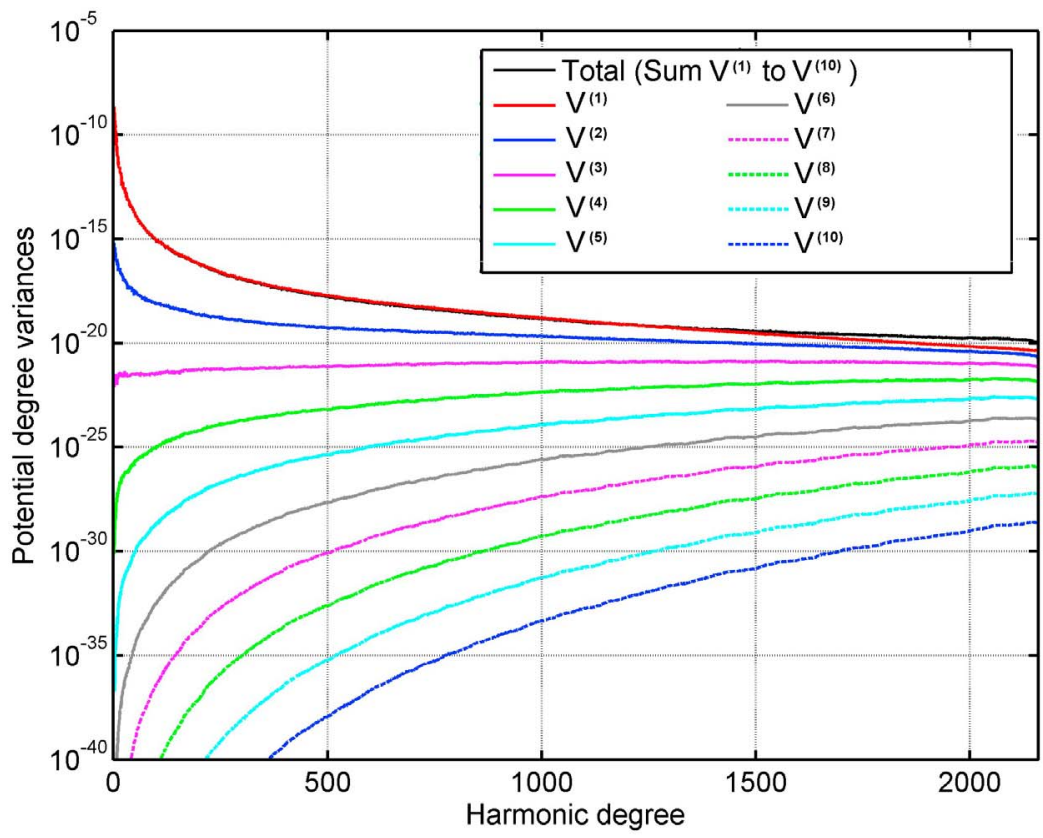

Figure 1. Potential degree variances (dimensionless) of Earth's topographic potential to $p_{\max }=10$ (black), and contributions $V^{(1)}$ to $V^{(10)}$.

[27] It is important to mention that higher powers of the topographic height function should be sampled with higher spatial resolution to allow for correct evaluation of highdegree harmonic coefficients. Therefore, we use grids of higher spatial resolution (e.g., $2^{\prime} \times 2^{\prime}$ ) than would be required to derive the spherical harmonic coefficients up to $\mathrm{n}=2160$ corresponding to a spatial resolution of $5^{\prime} \times 5^{\prime}$ (half-wavelength) on the sphere.

\subsection{Spectra of Earth's Topographic Potential}

[28] The dimensionless topographic potential degree variance $\sigma_{n}$ [e.g., Rapp, 1982]

$$
\sigma_{n}^{2}=\sum_{m=1}^{m}\left(\bar{C}_{n m}^{2}+\bar{S}_{n m}^{2}\right)
$$

of all (single) contributions $V_{n m}^{(p)}$ (see Appendix A, equations (A1)-(A10) for explicit forms) and the total contribution $V_{n m}^{p \max =10}$ are shown in Figure 1. From the topographic potential degree variances shown in Figure 1, the graphs for $p \leq 3$ have been published (e.g., by Novák and Grafarend [2006] to $n_{\max }=360$, by Makhloof [2007, p. 101] to $n_{\max }=2000$, by Bagherbandi [2011, p. 152] to $n_{\max }=2160$, by Balmino et al. [2012, Figure 7] to $n_{\max }=10,800$ and the graphs for $p \leq 5$ by Novák [2010b] to $\left.n_{\max }=5,400\right)$, while the spectra of orders $p>5$ are little investigated in the literature for high-degree models.

[29] While the contribution of the linear and squared topography steadily decreases with increasing harmonic degree $n$, there is an opposite behavior visible for the higherorder terms with $p>2$. At low and medium harmonic degrees (say, to 360), the spectral power of the first six contributions ranges over more than 20 magnitudes of order, while this range diminishes to less than 4 magnitudes at high degrees (around 2000). This shows that higher-order terms make an increasingly more relevant contribution to the topographic potential as the harmonic degree increases.

[30] Bearing in mind that the square-root of the degree variances may better indicate the practical relevance of the $V^{(p)}$ contributions to the topographic potential in the space domain [see Balmino et al., 2012], it becomes obvious that at $n=2000 V^{(6)}$ reaches more than $1 \%$ and $V^{(4)}$ about $\sim 10 \%$ of the linear contribution $V^{(1)}$. This readily suggests that with today's high-degree models of Earth's topography, terms higher than $V^{(3)}$ are required to accurately describe the high-resolution potential of a given topography/density distribution.

[31] Figure 1 shows that at medium harmonic degrees of about 360, the (square-root) contribution of terms higher than $V^{(3)}$ is well below $1 \%$, as such insignificant in practice for degree-360 models. From Wieczorek's [2007] convergence analysis a similar conclusion can be drawn (compare Figure 9 of Wieczorek [2007]). It can be argued from Figure 1 that the high powers of the topography, say $p \geq 8$, could be dropped in practical applications, as they make a square-root contribution of no larger than $\sim 0.1 \%$ over the entire range of harmonic degrees shown in Figure 1. These low-contribution terms are included here up to $p=10$ to yield precise reference values of the topographic potential, allowing for a reliable analysis of truncation errors when considering less terms (e.g., $p<10$ ).

\subsection{Convergence of the Series in the Spatial Domain}

[32] Though the topographic potential degree variance spectra reveal the relative importance of the higher-order powers of the topography beyond harmonic degree of $\sim 1000$, numerical tests in the spatial domain are necessary to quantify truncation errors in terms of topographic 

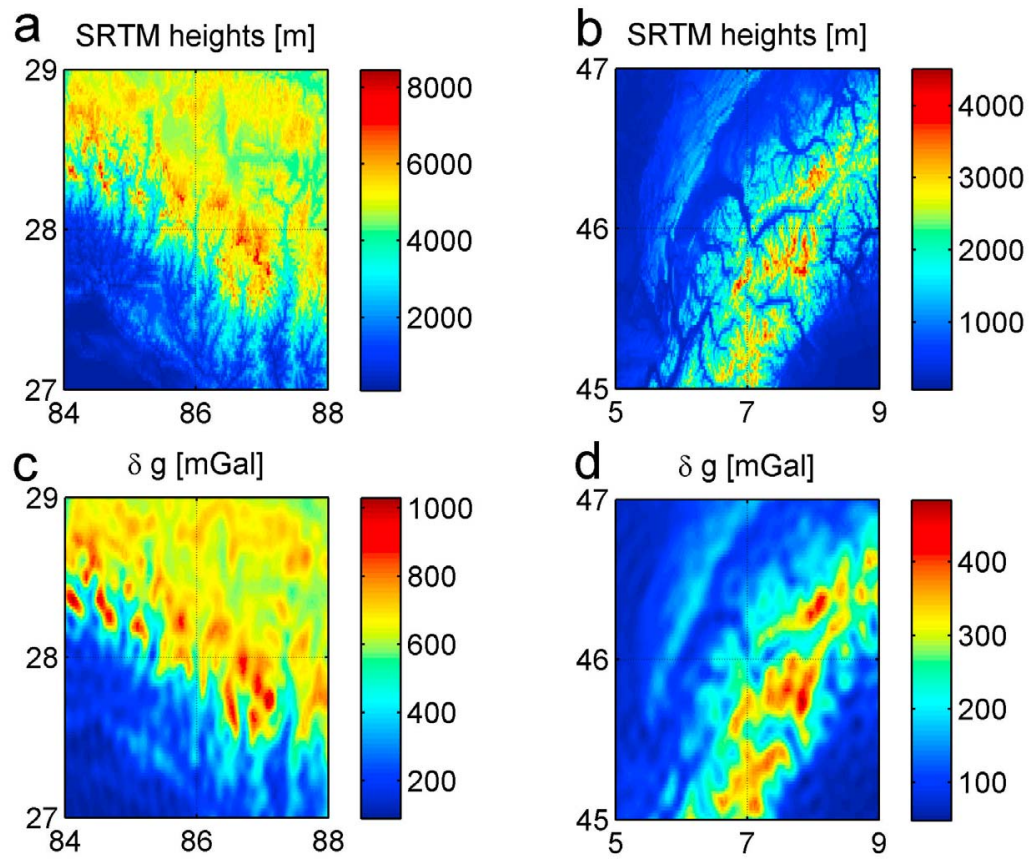

Figure 2. ( $a$ and b) Topography (from SRTM) and (c and d) topographic gravity effects (from DTM2006 to degree 2160) over the test areas Himalayas (Figures $2 \mathrm{a}$ and $2 \mathrm{c}$ ) and European Alps (Figures 2b and 2d), coordinates are in terms of geocentric latitude and longitude.

gravity effects. The application of series expansions of the topographic potential to compute topographic gravity effects at the Earth's surface is essentially governed by two series expansions.

[33] 1. The first is the series expansions of the topographic potential itself, used to transform the powers of the topography to topographic potential and gravity effects (equations (4) and (5)).

[34] 2. The second is used to upward-continue the topographic gravity effects from some reference surface to the Earth's topography (equations (7) and (8)).

[35] First we analyze approximation errors of the continuation of topographic gravity effects to the Earth's surface with a Taylor series expansion limited to $k_{\max }$ followed by an analysis of truncation errors resulting from dropping the higher-order powers of the topography beyond $p_{\text {max }}$. Because our tests involve topographic gravity effects computations at the Earth's surface, the direct 3D SHS technique (variant 1 in section 2.2) is too time-consuming to study the convergence over the entire surface of Earth. Over smaller regions, however, SHS at the 3D locations of the topography is feasible within acceptable computation times [cf. Hirt, 2012].

[36] We therefore choose two test areas of regional extent with extreme and moderate topography (Figures $2 \mathrm{a}$ and $2 \mathrm{~b}$ ). The Himalaya region $\left(27^{\circ}<\varphi<29^{\circ}, 84^{\circ}<\lambda<88^{\circ}\right)$ includes the Mount Everest summit and the North Indian plains with the SRTM topography extending over a range of more than $8,000 \mathrm{~m}$. The European Alps region $\left(45^{\circ}<\varphi<47^{\circ}, 5^{\circ}<\lambda<9^{\circ}\right)$ features an elevation range of $4,500 \mathrm{~m}$. While the MountEverest region should be indicative for a worst-case error estimate for Earth, the European Alps area serves as an example of a moderately rugged mountain range. In all subsequent tests, we consider a 1-mGal-level acceptable for practical applications. The computation points are arranged in terms of $0.02^{\circ}$ resolution grids regularly spaced in geocentric latitude and longitude, giving 20,000 points per test region. Elevations representing the Earth's surface were interpolated bicubically from the $1 \mathrm{~km}$ SRTM version 4.1 release from Jarvis et al. [2008], whereby the difference between geodetic and geocentric latitude was taken into account [see Torge, 2001, p. 95].

\subsubsection{Gravity Upward-Continuation Tests}

[37] We computed true values $\delta g_{Q}^{\text {true }}$ at the $3 \mathrm{D}$-locations of the SRTM-topography with an expansion up to $p_{\max }=10$ (Figures $2 \mathrm{c}$ and $2 \mathrm{~d}$ ). We then evaluated $\delta g$ (equation (5)) and radial derivatives $\partial^{k} \delta g / \partial r^{k}$ (equation (7)) for $k \leq 6$ both at the surface of the reference sphere $(R=6,378,137 \mathrm{~m}$ and $\left.H_{\text {ref }}=0\right)$ and at a reference height of $H_{\text {ref }}=4,000 \mathrm{~m}$ above $R$ (i.e., $R+H_{r e f}=6,382,137 \mathrm{~m}$ ) and used these grids along with SRTM height information $H$ for the continuation of topographic gravity effects to the Earth's surface (equations (6) and (8)). For the Himalaya region, Figure 3 shows the differences between $\delta g_{Q}^{\text {true }}$ and $\delta g_{Q}^{k \text { max }}$ as a function of the parameter $k_{\max }$ for the case $H_{\text {ref }}=0 \mathrm{~m}$, and Figure 4 the respective differences for the case $H_{r e f}=4,000 \mathrm{~m}$.

[38] From Figure 3, the convergence of the upward-continuation is relatively slow when $H_{r e f}=0 \mathrm{~m}$, with the differences $\delta g_{Q}^{\text {true }}$ minus $\delta g_{Q}^{k \max }$ exceeding values of $100 \mathrm{mGal}$ for $k_{\max }=5$. Using an average reference height $H_{\text {ref }}=$ $4,000 \mathrm{~m}$ in the upward continuation significantly shortens the distances $H-H_{r e f}$ along which the gravity values are continued. As a result, the convergence is considerably improved [Holmes, 2003; Hirt, 2012], with approximation errors $\delta g_{Q}^{\text {true }}$ minus $\delta g_{Q}^{k \text { max }}$ falling below the mGal-level for $k_{\max }=5$ (cf. Table 1 and Figure 4) over the most rugged area of Earth. Repetition of the same test over the European Alps 

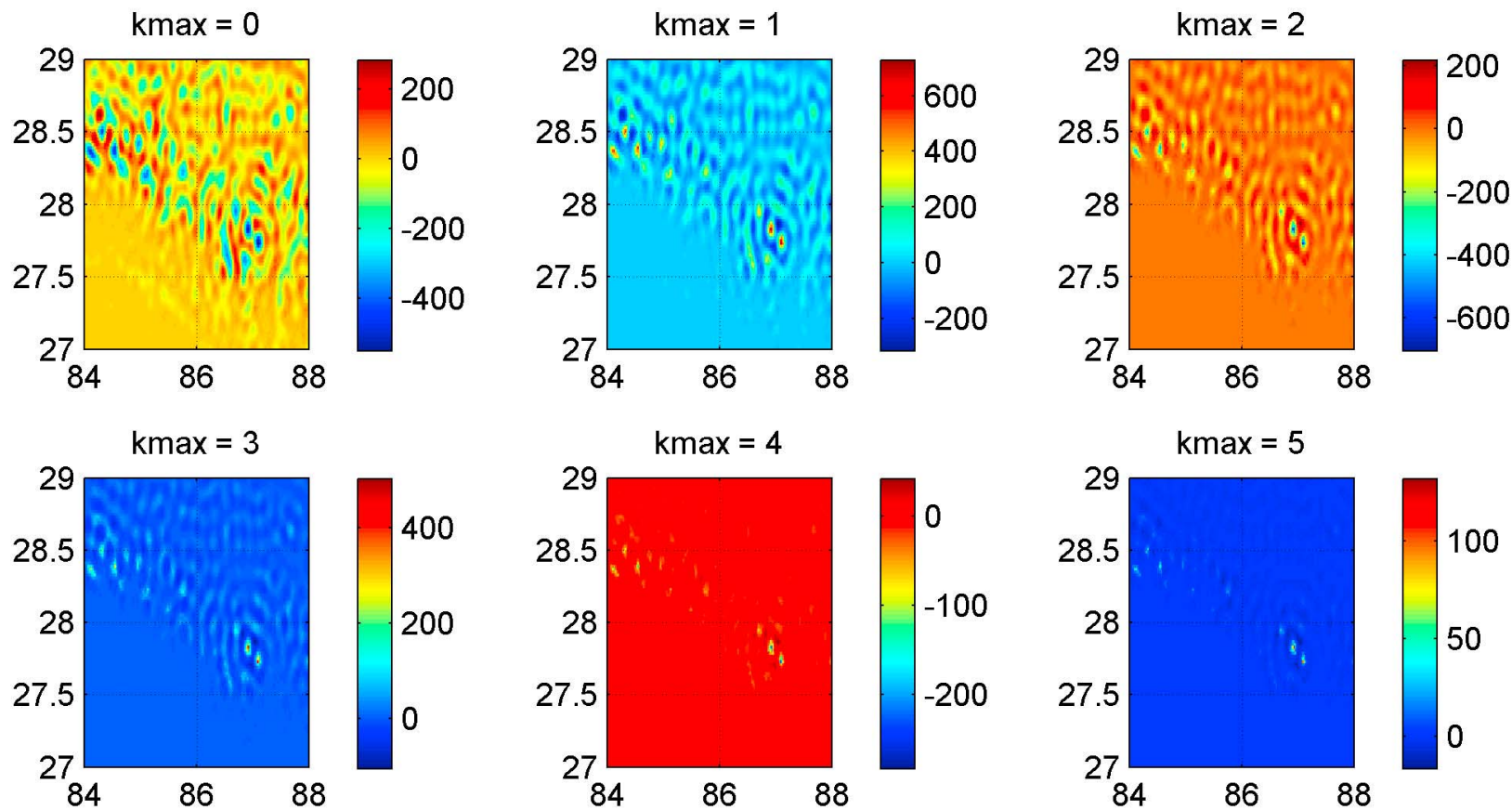

Figure 3. Approximation errors of upward-continued gravity as a function of $k_{\max }$ with reference height $H_{r e f}=0 \mathrm{~m}$, test area is the Himalaya region, coordinates are in terms of geocentric latitude and longitude, unit in mGal.

area shows that a fourth-order series expansion and $H_{r e f}=$ $4,000 \mathrm{~m}$ is capable of reducing approximation errors below the mGal-level (cf. Table 2), which is a useful indication for other areas with comparable or less rugged topography. We acknowledge that the reference height $H_{r e f}$ could be chosen smaller, say 2,000 m ( average elevation of the Alps) which would result in an even better convergence over the European Alps. Using a single constant value of $4,000 \mathrm{~m}$ is more
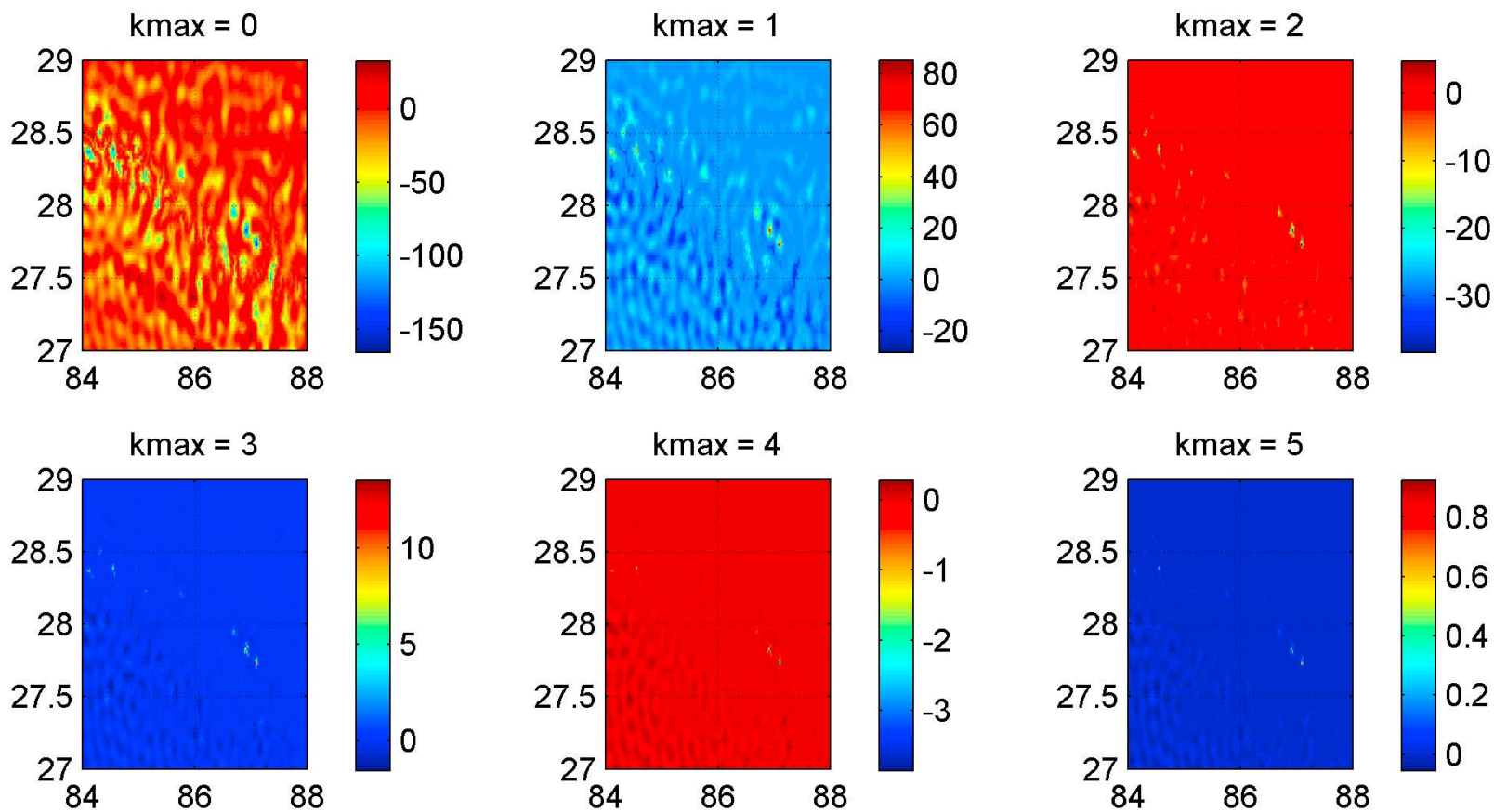

Figure 4. Approximation errors of upward-continued gravity over the Himalaya region as a function of $k_{\max }$, with reference height $H_{r e f}=4000 \mathrm{~m}$, unit in $\mathrm{mGal}$. 
Table 1. Approximation Errors of Upward-Continued Gravity Over the Himalaya Region as a Function of the Taylor Series Expansion Degree $k_{\max }{ }^{a}$

\begin{tabular}{|c|c|c|c|c|c|c|c|c|}
\hline \multirow[b]{2}{*}{ Expansion Degree $k_{\max }$} & \multicolumn{4}{|c|}{ Reference Height $H_{r e f}=0 \mathrm{~m}$} & \multicolumn{4}{|c|}{ Reference Height $H_{r e f}=4000 \mathrm{~m}$} \\
\hline & Min & $\operatorname{Max}$ & Mean & RMS & Min & Max & Mean & RMS \\
\hline 0 & -551.21 & 284.12 & -13.60 & 74.98 & -165.77 & 32.68 & -8.59 & 17.67 \\
\hline 1 & -315.88 & 728.36 & 5.47 & 59.75 & -28.20 & 85.05 & -0.07 & 4.11 \\
\hline 2 & -703.36 & 218.29 & -3.29 & 35.87 & -38.34 & 4.76 & -0.16 & 1.07 \\
\hline 3 & -105.41 & 502.41 & 1.59 & 17.20 & -1.56 & 13.54 & 0.00 & 0.27 \\
\hline 4 & -283.41 & 42.21 & -0.62 & 7.02 & -3.86 & 0.28 & 0.00 & 0.06 \\
\hline 5 & -16.49 & 132.18 & 0.21 & 2.54 & -0.05 & 0.93 & 0.00 & 0.01 \\
\hline 6 & -52.55 & 5.48 & -0.06 & 0.83 & -0.18 & 0.01 & 0.00 & 0.01 \\
\hline
\end{tabular}

${ }^{\mathrm{a}}$ Units in mGal.

convenient, and gives acceptable results not only over both areas, but very likely over entire Earth.

\subsubsection{Convergence Tests}

[39] Here we answer the question how many powers of the topography should be included in the evaluation of series expansions of the topographic potential and the frequently used $n_{\max }=2160$ in order to force truncation errors below the 1-mGal-threshold. From the spectral analysis (Figure 1), we conclude that inclusion of terms higher than $p_{\max }=10$ would not lead to any perceptible topographic gravity effects differences when compared to $p_{\max }=10$. We therefore use $p_{\max }=10$ as 'true' comparison values to quantify truncation errors, similar to the tests by Wieczorek [2007].

\subsubsection{Test A: Truncation Errors}

\section{at the Reference Sphere}

[40] Over the Himalaya region, Figure 5 shows the truncation error defined as $\delta g^{p \max =10}$ minus $\delta g^{p \max \in[1 . .6]}$, computed at the surface of the reference sphere (equation (5)). For $p_{\max }=3$, the value sometimes used in practice with degree-2160 models, truncation errors exceed the $100 \mathrm{mGal}$ level. Inclusion of each additional term reduces the maximum truncation errors by a factor of $\sim 2$ to $\sim 3$. Taking into account the powers to $p_{\max }=6$ reduces maximum errors to $\sim 5 \mathrm{mGal}$, while expansion to $p_{\max }=8$ diminishes truncation errors to less than $1 \mathrm{mGal}$ (cf. Table 3). Over the European Alps region, limitation to quartic terms $\left(p_{\max }=4\right)$ is sufficient to make truncation errors smaller than $1 \mathrm{mGal}$ (Table 4).

\subsubsection{Test B: Truncation Errors at the Topography}

[41] Truncation errors computed at the sphere do not take into account the effect of gravity attenuation, and can be over-estimates if topographic gravity effects are required at the surface of the topography. We therefore examined the truncation errors at the topography by using the successfully tested upward-continuation procedure (cf. section 3.3.1) with $H_{r e f}=4,000 \mathrm{~m}$, and $k_{\max }=6$, which is more than sufficient for accurate 3D-SHS (see Tables 1 and 2). In comparisons to truncation error tests at the sphere, truncation errors at the topography are always smaller for the same $p_{\text {max }}$, compare Figure 5 with Figure 6. Maximum truncation errors for the Himalaya area are at the $\sim 25 \mathrm{mGal}$ level for $p_{\text {max }}=3$, and fall below the 1-mGal-threshold for $p_{\max }=6$ (Table 3). For the European Alps region, convergence is reached for $p_{\max }=4$ (Table 4 ).

\section{Discussion}

[42] The computation of topographic gravity effects at the Earth's surface from degree-2160 models of Earth's topography is accomplished through a combination of two series expansions, the first to convert topography to topographic potential and topographic gravity at the reference sphere, and the second to upward-continue topographic gravity effects to the Earth's surface, and thus to account for gravity attenuation with height. Both series expansions (cf. equations (4) and (8)) have notable similarities, in that, they expand topographic gravity into powers of the topography, and depend on binomial coefficients. While the first uses powers of heights in the spectral domain, the second uses them in the spatial domain.

[43] If topographic gravity effects are sought at the reference sphere (this may be the case e.g., when comparison data such coefficients of a gravitational potential model would be given at the radius of the same reference sphere), the second expansion is not required. Also, over small areas SHS performed directly at the 3D locations of the topography (equation (5)) can replace the second expansion. Nonetheless if topographic gravity effects are required at the

Table 2. Approximation Errors of Upward-Continued Gravity Over the European Alps as a Function of the Taylor Series Expansion Degree $k_{\max }{ }^{a}$

\begin{tabular}{|c|c|c|c|c|c|c|c|c|}
\hline \multirow[b]{2}{*}{ Expansion Degree $k_{\max }$} & \multicolumn{4}{|c|}{ Reference Height $H_{r e f}=0 \mathrm{~m}$} & \multicolumn{4}{|c|}{ Reference Height $H_{r e f}=4000 \mathrm{~m}$} \\
\hline & Min & Max & Mean & RMS & Min & Max & Mean & RMS \\
\hline 0 & -122.27 & 48.17 & -3.90 & 16.12 & -82.66 & 43.22 & -1.25 & 13.04 \\
\hline 1 & -23.14 & 59.19 & 0.78 & 4.92 & -33.17 & 13.90 & -0.80 & 4.04 \\
\hline 2 & -24.44 & 11.76 & -0.19 & 1.36 & -9.71 & 3.63 & -0.20 & 1.06 \\
\hline 3 & -3.76 & 8.05 & 0.03 & 0.32 & -2.33 & 1.06 & -0.05 & 0.24 \\
\hline 4 & -2.19 & 0.94 & -0.01 & 0.07 & -0.47 & 0.26 & -0.01 & 0.05 \\
\hline 5 & -0.20 & 0.49 & -0.01 & 0.01 & -0.09 & 0.05 & -0.01 & 0.01 \\
\hline 6 & -0.11 & 0.02 & -0.01 & 0.01 & -0.02 & 0.00 & -0.01 & 0.01 \\
\hline
\end{tabular}

${ }^{\mathrm{a}}$ Units in $\mathrm{mGal}$. 

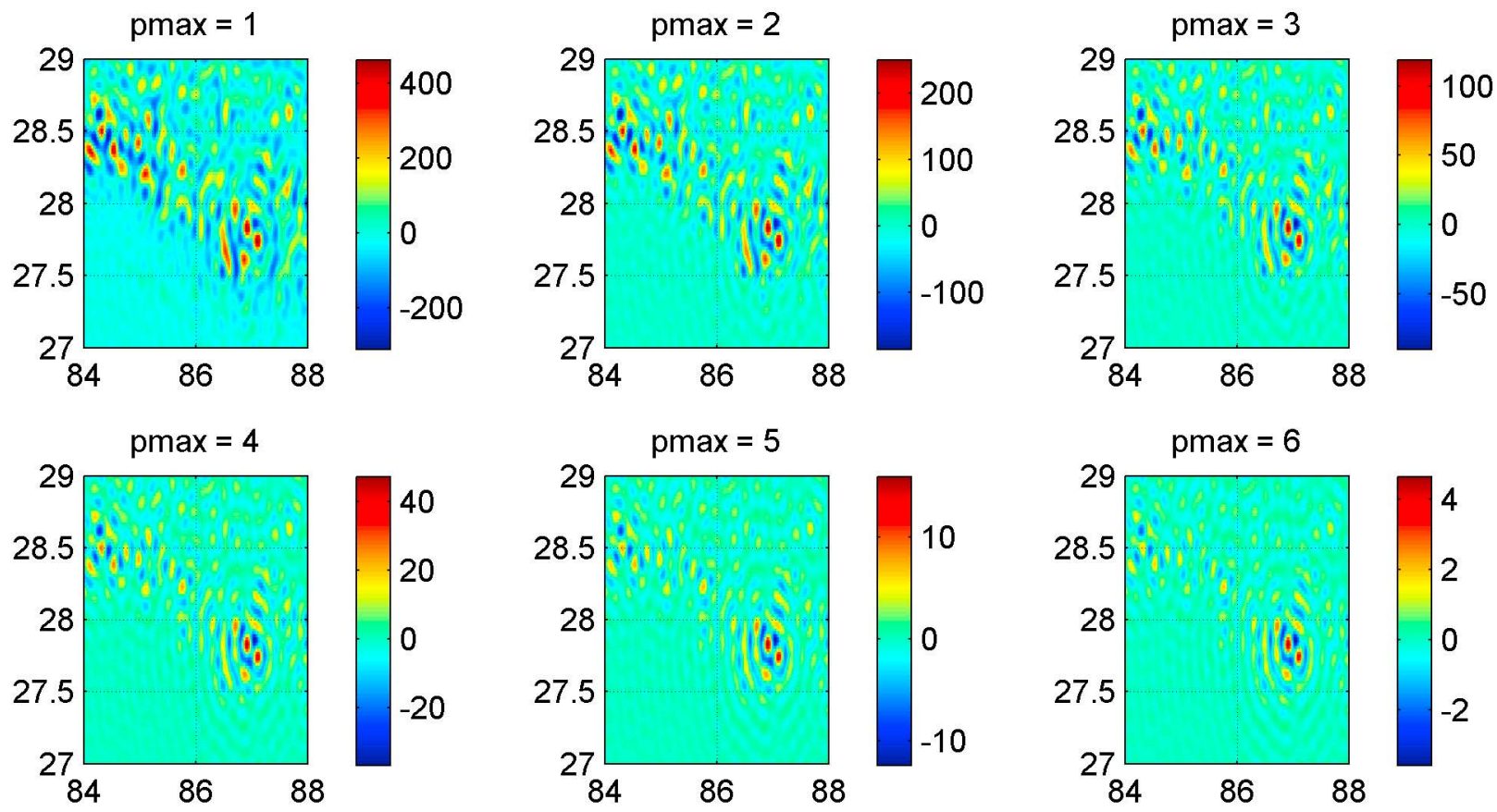

Figure 5. Truncation errors of gravity at the surface of the reference sphere over the Himalaya region as a function of $p_{\max }$, unit in $\mathrm{mGal}$.

Earth's surface in terms of densely spaced multiple grid points, the use of two series expansions offers a pragmatic solution that keeps SHS computation times manageably small [see Hirt, 2012].

[44] Our convergence analysis (section 3) showed that limitation to the first three powers of the topography $\left(p_{\max }=3\right)$ gives rise to truncation errors exceeding $100 \mathrm{mGal}$ at the reference sphere, and $\sim 25 \mathrm{mGal}$ at the topography. Inclusion of the higher-order terms to the 7 th power reduces truncation errors to the $\mathrm{mGal}-$ level over the Himalaya region. Because of the demanding computational requirements for direct 3D SHS (without Taylor upward-continuation) we were unable to test truncation errors over entire Earth. Nonetheless, the chosen Himalaya Mountains test area is likely to yield reasonable worst-case error estimates.

[45] As a key finding of our study, both series expansions of the topographic potential and the upward-continuation of topographic gravity effects require a comparable number of terms ( $p_{\max }=6$ and $k_{\max }=5$, which are six terms including 0th-order) to converge over the Himalayas, and $p_{\max }=$ $k_{\max }=4$ over the European Alps region. This behavior might be explained by the similarities evident among the series expansions used.

[46] Our results differ from Balmino et al. [2012], who investigated topographic gravity effects to ultra-high harmonic degree of 10,800. They limited the series expansions to $p_{\max }=3$ (while acknowledging this value might be too small) and used a large $k_{\max }=40$ for the upward-continuation of gravity with Taylor expansions of the attenuation factor itself. Balmino et al.'s [2012] results are not directly comparable with our study because of the ultra-high degree of 10,800 of their topography model, and the fact they did not use reference heights $H_{\text {ref }}$ to improve the convergence of the upward-continuation. Nonetheless our study suggests first that with ultra high-degree topography models, $p_{\max }$ should be considerably larger than 3 . Second, the use of reference

Table 3. Truncation Errors of Gravity Over the Himalaya Region as a Function of $p_{\max }{ }^{\mathrm{a}}$

\begin{tabular}{|c|c|c|c|c|c|c|c|c|}
\hline \multirow[b]{2}{*}{ Expansion Degree $p_{\max }$} & \multicolumn{4}{|c|}{ Case A at the Sphere } & \multicolumn{4}{|c|}{ Case B at the Topography } \\
\hline & Min & Max & Mean & RMS & Min & Max & Mean & RMS \\
\hline 1 & -309.69 & 462.06 & 2.34 & 72.49 & -134.16 & 129.34 & 0.01 & 27.78 \\
\hline 2 & -185.85 & 250.29 & 0.01 & 35.73 & -58.09 & 52.76 & -0.68 & 10.44 \\
\hline 3 & -90.09 & 119.03 & -0.01 & 15.10 & -24.08 & 21.60 & -0.21 & 3.97 \\
\hline 4 & -36.64 & 47.36 & -0.00 & 5.42 & -8.38 & 7.73 & -0.06 & 1.36 \\
\hline 5 & -12.37 & 15.96 & -0.00 & 1.68 & -2.47 & 2.40 & -0.01 & 0.42 \\
\hline 6 & -3.57 & 4.64 & -0.00 & 0.46 & -0.63 & 0.65 & 0.00 & 0.11 \\
\hline 7 & -0.90 & 1.18 & -0.00 & 0.11 & -0.15 & 0.16 & 0.00 & 0.03 \\
\hline 8 & -0.20 & 0.26 & -0.00 & 0.02 & -0.17 & 0.04 & 0.00 & 0.01 \\
\hline
\end{tabular}

\footnotetext{
${ }^{\mathrm{a}}$ Units in $\mathrm{mGal}$.
} 
Table 4. Truncation Errors of Gravity Over the European Alps as a Function of $p_{\max }{ }^{a}$

\begin{tabular}{|c|c|c|c|c|c|c|c|c|}
\hline \multirow[b]{2}{*}{ Expansion Degree $p_{\max }$} & \multicolumn{4}{|c|}{ Case A at the Sphere } & \multicolumn{4}{|c|}{ Case B at the Topography } \\
\hline & Min & Max & Mean & RMS & Min & Max & Mean & RMS \\
\hline 1 & -57.78 & 91.24 & 0.35 & 14.55 & -48.89 & 50.80 & -0.20 & 9.63 \\
\hline 2 & -18.56 & 22.64 & -0.01 & 3.41 & -13.07 & 11.30 & -0.11 & 2.03 \\
\hline 3 & -4.62 & 4.78 & -0.00 & 0.70 & -3.02 & 2.17 & -0.02 & 0.40 \\
\hline 4 & -0.89 & 0.90 & -0.00 & 0.12 & -0.57 & 0.35 & -0.01 & 0.07 \\
\hline 5 & -0.14 & 0.14 & -0.00 & 0.02 & -0.10 & 0.05 & -0.01 & 0.01 \\
\hline 7 & -0.00 & 0.00 & 0.00 & 0.00 & -0.00 & 0.00 & 0.00 & 0.00 \\
\hline 8 & -0.00 & 0.00 & 0.00 & 0.00 & -0.00 & 0.00 & 0.00 & 0.00 \\
\hline
\end{tabular}

${ }^{\mathrm{a}}$ Units in $\mathrm{mGal}$.

heights $H_{r e f}$ will accelerate the upward-continuation convergence, suggesting $k_{\max }$ could be well below 40 . With the software available for our study, we cannot (yet) provide exact values for $p_{\max }$ and $k_{\max }$ for topographic gravity effects from ultra-high degree topography models.

[47] We also compared our results to the study by Sun and Sjöberg [2001]. They investigated the convergence and optimal truncation of binomial expansions of the attenuation factor and found that $k_{\max }=7$ yields a truncation error of less than $1 \%$ for $n_{\max }=2160$ and an elevation of 9,000 $\mathrm{m} \mathrm{[Sun}$ and Sjöberg, 2001, p. 634]. Opposed to our numerical tests, Sun and Sjöberg restricted their investigation to the attenuation factor itself, without including empirical coefficients $(\overline{H C}, \overline{H S})_{n m}^{p}$ to $n_{\max }=2160$, and without using the reference height $H_{\text {ref }}$ to accelerate the convergence. From our Tables 1 and 2 it is evident a smaller value of $k_{\max }=4$ would be sufficient to reach a comparable precision level, if reference heights are used.

[48] Finally, it is worth mentioning that Balmino et al. [2012] found that the contributions of the first three powers of the topography reach comparable signal strength at about degree 3,000 , with the third-order $V^{(3)}$ contribution being larger than that of $V^{(2)}$, and $V^{(2)}$ being larger than $V^{(1)}$ in harmonic band $\sim 3,000$ to 10,800 . This demonstrates the importance of inclusion of higher-order powers of the topography for the computation of topographic gravity effects. With ultra-high degree harmonic models, it is reasonable to expect a similar behavior for at least some of the terms higher than third-order (Novák [2010b] already demonstrated this for $n_{\max }=5400$ and $p_{\max }=5$ ).

\section{Conclusions}

[49] For degree-2160 models of Earth's topography, this study investigated the effect of truncating the series expansions of the topographic potential. Limitation of series expansions of the topographic potential to the first three powers of the topography gives rise to truncation errors of more than $100 \mathrm{mGal}$ (at the sphere) and $\sim 25 \mathrm{mGal}$ (at the topography) over regions with extreme topography, while not safely reaching the 1-mGal-level over a moderately rugged area. To keep truncation errors below the mGal-
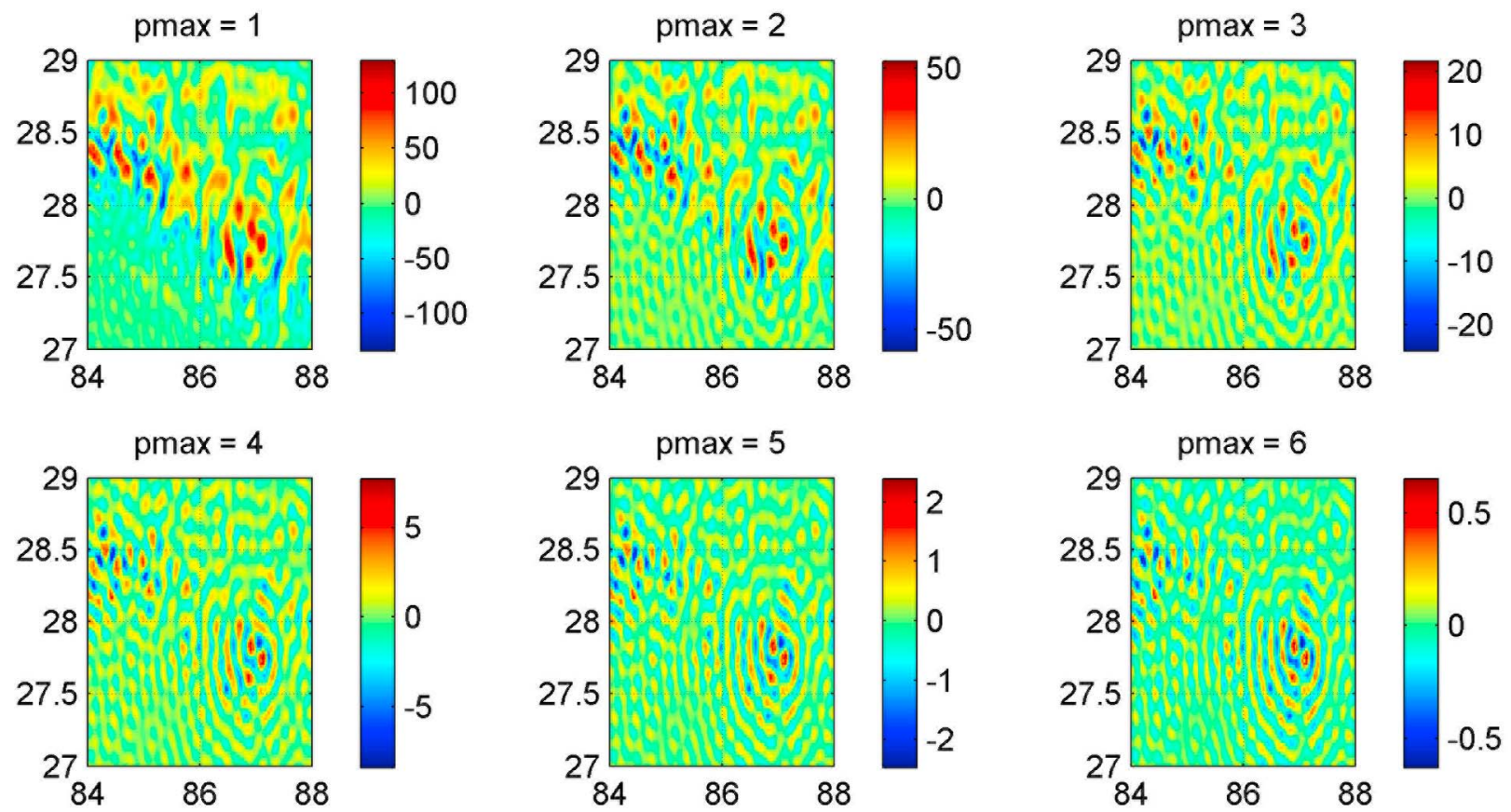

Figure 6. Truncation errors of upward-continued gravity over the Himalaya region as a function of $p_{\max }$ unit in mGal. 
level, the first seven powers of the topography should be included in the series expansions of the topographic potential. The higher-order powers of the topography were found to make a significant contribution to the topographic potential at short wavelengths, say harmonic degrees $\sim 1000$ to 2160 . We have further shown that a Taylor series expansion to fifth-order can be used to upward-continue topographic gravity effects to the Earth's surface with mGalprecision over areas of extreme topography. The use of reference heights significantly accelerates the convergence of the gravity continuation with Taylor expansions.

[50] The results of this study are relevant for any geophysical application of the degree-2160 EGM2008 geopotential model where accurate values of the topographic potential are required at the same resolution. Example applications include the construction of spherical harmonic Bouguer gravity anomaly maps and gravity inversion, but also topographic reductions (terrain corrections) in spherical harmonics. Finally, for all future studies dealing with the use of high-degree topographic potential models, e.g., for Moon, Mars or other planetary bodies, the higher-order terms of the topography as well as the upward-continuation process could be investigated with approaches similar to those described in this paper.

\section{Appendix A}

[51] The contributions $V_{n m}^{(p)}$ of the linear, quadratic, cubic, quartic, up to the 10th-power of the topography $H_{n m}^{(p)}$ to the topographic potential

$$
V_{n m}^{p \max =10}=\sum_{p=1}^{10} V_{n m}^{(p)}
$$

read in explicit form

$$
\begin{aligned}
& V_{n m}^{(1)}=\frac{3}{(2 n+1)} \cdot \frac{\rho}{\bar{\rho}} H_{n m}^{(1)} \\
& V_{n m}^{(2)}=\frac{3(n+2)}{2(2 n+1)} \cdot \frac{\rho}{\bar{\rho}} H_{n m}^{(2)} \\
& V_{n m}^{(3)}=\frac{3(n+2)(n+1)}{6(2 n+1)} \cdot \frac{\rho}{\bar{\rho}} H_{n m}^{(3)} \\
& V_{n m}^{(4)}=\frac{3(n+2)(n+1) n}{24(2 n+1)} \cdot \frac{\rho}{\bar{\rho}} H_{n m}^{(4)} \\
& V_{n m}^{(5)}=\frac{3(n+2)(n+1) n(n-1)}{120(2 n+1)} \cdot \frac{\rho}{\bar{\rho}} H_{n m}^{(5)} \\
& V_{n m}^{(6)}=\frac{3(n+2)(n+1) n(n-1)(n-2)}{720(2 n+1)} \cdot \frac{\rho}{\bar{\rho}} H_{n m}^{(6)} \\
& V_{n m}^{(7)}=\frac{3(n+2)(n+1) n(n-1)(n-2)(n-3)}{5040(2 n+1)} \cdot \frac{\rho}{\bar{\rho}} H_{n m}^{(7)} \\
& V_{n m}^{(8)}=\frac{3(n+2)(n+1) n(n-1)(n-2)(n-3)(n-4)}{40320(2 n+1)} \\
& \cdot \frac{\rho}{\bar{\rho}} H_{n m}^{(8)}
\end{aligned}
$$

$$
V_{n m}^{(9)}=\frac{3(n+2)(n+1) n(n-1)(n-2)(n-3)(n-4)(n-5)}{362880(2 n+1)} \cdot \frac{\rho}{\bar{\rho}} H_{n m}^{(9)}
$$

$$
\begin{aligned}
V_{n m}^{(10)}= & \frac{3(n+2)(n+1) n(n-1)(n-2)(n-3)(n-4)(n-5)(n-6)}{3628800(2 n+1)} \\
& \cdot \frac{\rho}{\bar{\rho}} H_{n m}^{(10)} .
\end{aligned}
$$

[52] Acknowledgments. We thank the Australian Research Council (ARC) for funding through discovery project grant DP120102441. Sincere thanks go to the two anonymous reviewers for their very constructive comments, and to Tom Parsons for handling of our manuscript. Our spherical harmonic analyses were performed using the freely available software archive SHTOOLS (shtools.ipgp.fr). This is The Institute for Geoscience Research publication 428 .

\section{References}

Bagherbandi, M. (2011), An isostatic Earth crustal model and its applications, PhD dissertation, Div. of Geod. and Geoinf., R. Inst. of Technol., Stockholm.

Bagherbandi, M., and L. E. Sjöberg (2012), A synthetic Earth gravity model based on a topographic-isostatic model, Stud. Geophys. Geod., doi:10.1007/s11200-011-9045-1, in press.

Balmino, G. (1994), Gravitational potential harmonics from the shape of an homogeneous body, Celestial Mech. Dyn. Astron., 60(3), 331-364, doi:10.1007/BF00691901.

Balmino, G., N. Vales, S. Bonvalot, and A. Briais (2012), Spherical harmonic modelling to ultra-high degree of Bouguer and isostatic anomalies, J. Geod., 86(7), 499-520, doi:10.1007/s00190-011-0533-4.

Chambat, F., and B. Valette (2005), Earth gravity up to second order in topography and density, Phys. Earth Planet. Inter., 151(1-2), 89-106, doi:10.1016/j.pepi.2005.01.002.

Driscoll, J. R., and D. M. Healy (1994), Computing Fourier transforms and convolutions on the 2-sphere, Adv. Appl. Math., 15(2), 202-250, doi:10.1006/aama.1994.1008.

Eshagh, M. (2010), Comparison of two approaches for considering laterally varying density in topographic effect on satellite gravity gradiometric data, Acta Geophys., 58(4), 661-686, doi:10.2478/s11600-009-0057-y.

Forsberg, R. (1984), A study of terrain reductions, density anomalies and geophysical inversion methods in gravity field modeling, Rep. 355, Dep. of Geod. Sci. and Surv., Ohio State Univ., Columbus.

Göttl, F., and R. Rummel (2009), A geodetic view on isostatic models, Pure Appl. Geophys., 166(8-9), 1247-1260, doi:10.1007/s00024-004-0489-x.

Gruber, C., P. Novák, F. Flechtner, and F. Barthelmes (2012), Derivation of the topographic potential from global DEM models, in International Association of Geodesy Symposia, Springer, Berlin, in press.

Hackney, R. I., and W. E. Featherstone (2003a), Geodetic versus geophysical perspectives of the 'gravity anomaly, Geophys. J. Int., 154(1), 35-43, doi:10.1046/j.1365-246X.2003.01941.x.

Hackney, R. I., and W. E. Featherstone (2003b), Erratum, Geophys. J. Int., 154(2), 596, doi:10.1046/j.1365-246X.2003.02058.x.

Hackney, R. I., and W. E. Featherstone (2006), Corrigendum, Geophys. J. Int., 167(6), 585, doi:10.1111/j.1365-246X.2006.03035.x.

Heck, B. (2003), On Helmert's methods of condensation, J. Geod., 77(3-4), 155-170, doi:10.1007/s00190-003-0318-5.

Hirt, C. (2012), Efficient and accurate high-degree spherical harmonic synthesis of gravity field functionals at the Earth's surface using the gradient approach, J. Geod., 86(9), 729-744, doi:10.1007/s00190-012-0550-y.

Hirt, C., T. Gruber, and W. Featherstone (2011), Evaluation of the first GOCE static gravity field models using terrestrial gravity, vertical deflections and EGM2008 quasigeoid heights, J. Geod., 85(10), 723-740, doi:10.1007/s00190-011-0482-y.

Hirt, C., M. Kuhn, W. E. Featherstone, and F. Göttl (2012), Topographic/ isostatic evaluation of new-generation GOCE gravity field models, J. Geophys. Res., 117, B05407, doi:10.1029/2011JB008878.

Holmes, S. A. (2003), High degree spherical harmonic synthesis for simulated Earth gravity modelling, PhD thesis, 171 pp., Dep. of Spatial Sci., Curtin Univ. of Technol., Perth, West. Aust., Australia.

Holmes, S. A., and W. E. Featherstone (2002), A unified approach to the Clenshaw summation and the recursive computation of very high degree and order normalized associated Legendre functions, J. Geod., 76(5), 279-299, doi:10.1007/s00190-002-0216-2. 
Holmes, S. A., and N. K. Pavlis (2008), Spherical harmonic synthesis software, Natl. Geospatial Intell. Agency, Springfield, Va. [Available at http://earth-info.nga.mil/GandG/wgs84/gravitymod/new_egm/new egm.html.]

Jarvis, A., H. I. Reuter, A. Nelson, and E. Guevara (2008), Hole-filled SRTM for the globe version 4, in SRTM 90 m Digital Elevation Data, http://srtm.csi.cgiar.org, CGIAR Consortium for Spatial Inf., Montpellier, France.

Jung, K. (1952), Die rechnerische Behandlung der Airyischen Isostasie mit einer Entwicklung des Quadrats der Meereshöhen nach Kugelfunktionen, Gerlands Beitr. Geophys., 62(1), 39-56.

Kuhn, M., and W. E. Featherstone (2003), On the optimal spatial resolution of crustal mass distributions for forward gravity field modelling, in Proceedings of the 3rd Meeting of the International Gravity and Geoid Commission, edited by I. Tziavos, pp. 195-200, Ziti, Tessaloniki.

Kuhn, M., and K. Seitz (2005), Comparison of Newton's integral in the space and frequency domains, in A Window on the Future of Geodesy, edited by F. Sanso, pp. 386-391, Springer, Berlin.

Kuhn, M., W. E. Featherstone, and J. F. Kirby (2009), Complete spherical Bouguer gravity anomalies over Australia, Aust. J. Earth Sci., 56(2), 213-223, doi:10.1080/08120090802547041.

Makhloof, A. A. (2007), The use of topographic-isostatic mass information in geodetic applications, $\mathrm{PhD}$ dissertation, Inst. für Geod. und Geoinf. der Univ. Bonn, Bonn, Germany.

Makhloof, A. A., and K.-H. Ilk (2008), Effects of topographic-isostatic masses on gravitational functionals at the Earth's surface and at airborne and satellite altitudes, J. Geod., 82(2), 93-111, doi:10.1007/s00190-0070159-8.

Martinec, Z. (1994), The density contrast at the Mohorovicic discontinuity, Geophys. J. Int., 117(2), 539-544, doi:10.1111/j.1365-246X.1994. tb03950.x.

Moritz, H. (1980), Advanced Physical Geodesy, Herbert Wichmann, Karlsruhe, Germany.

Moritz, H. (2000), Geodetic Reference System 1980, J. Geod., 74(1), 128-162, doi:10.1007/s001900050278

Nahavandchi, H., and L. E. Sjöberg (1998), Terrain corrections to power $\mathrm{H} 3$ in gravimetric geoid determination, J. Geod., 72(3), 124-135, doi:10.1007/s001900050154

Neumann, G. A., M. T. Zuber, M. A. Wieczorek, P. J. McGovern, F. G Lemoine, and D. E. Smith (2004), Crustal structure of Mars from gravity and topography, J. Geophys. Res., 109, E08002, doi:10.1029/ 2004JE002262.

Novák, P. (2010a), High resolution constituents of the Earth gravitational field, Surv. Geophys., 31(1), 1-21, doi:10.1007/s10712-009-9077-z.

Novák, P. (2010b), Direct modelling of the gravitational field using harmonic series, Acta Geodyn. Geomater., 7(1), 35-47.

Novák, P., and E. W. Grafarend (2006), The effect of topographical and atmospheric masses on spaceborne gravimetric and gradiometric data Stud. Geophys. Geod., 50(4), 549-582, doi:10.1007/s11200-006-0035-7.

Parker, R. L., and S. P. Huestis (1974), The inversion of magnetic anomalies in the presence of topography, J. Geophys. Res., 79(11), 1587-1593, doi:10.1029/JB079i011p01587.
Pavlis, N. K., J. K. Factor, and S. A. Holmes (2007), Terrain-related gravimetric quantities computed for the next EGM, Harita Dergisi, 18, 318-323.

Pavlis, N. K. S. A Holmes, S. C. Kenyon, and J. K. Factor (2008), An Earth gravitational model to degree 2160, paper presented at the 2008 General Assembly, Eur. Geosci. Union, Vienna, 13-18 April.

Pavlis, N. K. S. A. Holmes, S. C. Kenyon, and J. K. Factor (2012), The development and evaluation of the Earth Gravitational Model 2008 (EGM2008), J. Geophys. Res., 117, B04406, doi:10.1029/2011JB008916.

Ramillien, G. (2002), Gravity/magnetic potential of uneven shell topography, J. Geod., 76(3), 139-149, doi:10.1007/s00190-002-0193-5.

Rapp, R. H. (1982), Degree variances of the Earth's potential, topography and its isostatic compensation, Bull. Geod., 56(2), 84-94, doi:10.1007/ BF02525594.

Rummel, R., R. H. Rapp, H. Sünkel, and C. C. Tscherning (1988), Comparisons of global topographic/isostatic models to the Earth's observed gravity field, Rep. 388, Dep. of Geod. Sci. and Surv., Ohio State Univ., Columbus.

Sjöberg, L. E. (2000), Topographic effects by the Stokes-Helmert method of geoid and quasi-geoid determinations, J. Geod., 74(2), 255-268, doi:10.1007/s001900050284.

Sun, W., and L. E. Sjöberg (2001), Convergence and optimal truncation of binomial expansions used in isostatic compensations and terrain corrections, J. Geod., 74(9), 627-636, doi:10.1007/s001900000125.

Tenzer, R., P. Novák, and V. Gladkikh (2011a), On the accuracy of the bathymetry generated gravitational field quantities for a depth-dependent seawater density distribution, Stud. Geophys. Geod., 55, 609-626, doi:10.1007/s11200-010-0074-y.

Tenzer, R., P. Novák, and P. Vajda (2011b), Uniform spectral representation of the Earth's inner density structures and their gravitational field, Contrib. Geophys. Geod., 41(3), 191-209, doi:10.2478/v10126-0110007-y.

Torge, W. (2001), Geodesy, 3rd ed., de Gruyter, Berlin.

Tscherning, C. C., and K. Poder (1982), Some geodetic applications of Clenshaw summation, Boll. Geofis. Sci. Affini, 4, 351-364.

Tsoulis, D. (2001), A comparison between the Airy/Heiskanen and the Pratt/Hayford isostatic models for the computation of potential harmonic coefficients, J. Geod., 74(9), 637-643, doi:10.1007/s001900000124.

Vaníček, P., M. Najafi, Z. Martinec, L. Harrie, and L. E. Sjöberg (1995), Higher-degree reference field in the generalized Stokes-Helmert's scheme for geoid computation, J. Geod., 70(3), 176-182, doi:10.1007/ BF00943693.

Wieczorek, M. A. (2007), Gravity and topography of the terrestrial planets, in Treatise on Geophysics, vol. 10, Planets and Moons, edited by G. Schubert and T. Spohn, pp. 165-206, Elsevier, Oxford, U. K.

Wieczorek, M. A., and R. J. Phillips (1998), Potential anomalies on the sphere: Applications to the thickness of the lunar crust, J. Geophys. Res., 103(E1), 1715-1724, doi:10.1029/97JE03136.

Wild, F., and B. Heck (2005), A comparison of different isostatic models applied to satellite gravity gradiometry, in Gravity, Geoid and Space Missions, Int. Assoc. Geod. Symp., vol. 129, edited by C. Jekel, L. Bastos, and J. Fernandes, pp. 230-235, Springer, Berlin. 